\title{
Burden, risk factors and maternal and offspring outcomes of gestational diabetes mellitus (GDM) in sub-Saharan Africa (SSA): a systematic review and meta-analysis
}

\author{
Barnabas Kahiira Natamba ${ }^{1 *}$, Arthur Araali Namara ${ }^{1}$ and Moffat Joha Nyirenda ${ }^{1,2}$
}

\begin{abstract}
Background: The burden, determinants and outcomes of gestational diabetes mellitus (GDM) in sub-Saharan Africa are not known. We summarized existing evidence on the prevalence, risk factors and complications of GDM in the region.

Methods: PubMed was searched from inception to January 31st 2019. Studies were included if carried out in any of the sub-Saharan Africa countries and were available as abstracts or full texts. Interventional studies and those only including qualitative data were excluded. We employed random effects modelling to estimate the pooled GDM prevalence and risk ratios (RRs) for risk factors and outcomes of GDM and their $95 \% \mathrm{Cl}$.

Results: 283 papers were identified in the initial search, 33 of which met the inclusion criteria. Data on GDM burden suggest a pooled prevalence of $9 \%(95 \% \mathrm{Cl}, 7-12 \%)$. Family history of type 2 diabetes and previous history of GDM, macrosomia, stillbirth and abortion were important risk factors of GDM. In addition, being overweight or obese, over 25 years of age or hypertensive increased the risk of GDM. In terms of complications, GDM more than doubles the risk macrosomia (RR; 95\%Cl: $2.2 ; 1.1-4.4$ ).

Conclusions: There is a high burden of gestational diabetes mellitus in sub-Saharan Africa, but more studies are needed to document locally important risk factors as well as maternal and offspring outcomes. Interventions to reduce obesity among older African women might lead to reduced risk of GDM in sub-Saharan Africa.
\end{abstract}

Keywords: Gestational diabetes mellitus (GDM), Sub-Saharan Africa (SSA), Burden, Risk factors, Outcomes,

Prevalence, Overweight and obesity

\section{Background}

Gestational diabetes mellitus (GDM) is defined as "any degree of glucose intolerance that sets in or is first diagnosed during pregnancy" [1]. Estimates suggest that GDM prevalence is $7.0 \%$ in North America [2], 5.4\% in Europe [3] and $11.5 \%$ in Asia [4]. Differences in GDM prevalence across regions are, at least in part, due to methodological variations as there is currently little consensus on the appropriate methods to screen and

\footnotetext{
* Correspondence: Barnabas.Natamba@mrcuganda.org;

bknatamba@gmail.com

'MRC/UVRI and LSHTM Uganda Research Unit, Plot 51-59, Nakiwogo Road,

PO Box 49, Entebbe, Uganda

Full list of author information is available at the end of the article
}

diagnose GDM [1, 5-12]. Two-step screening and diagnosis methods, for example, are based on measurement of glucose concentration following a $50 \mathrm{~g}$ glucose challenge test (GCT) and then again after a $100 \mathrm{~g}$ oral glucose tolerance test (OGTT) [13]. On the other hand, one-step approaches only rely on the OGTT. In 2010, the International Association of Diabetes in Pregnancy Study Groups (IADPSG) endorsed a more stringent onestep screening and diagnostic criteria using $75 \mathrm{~g}$ OGTT [9] and this recommendation was adopted by the WHO in 2013 [12]. Adoption of the IADPSG 2010/WHO 2013 criteria is growing, although use of the other criteria still exists in many contexts.

(c) The Author(s). 2019 Open Access This article is distributed under the terms of the Creative Commons Attribution 4.0 International License (http://creativecommons.org/licenses/by/4.0/), which permits unrestricted use, distribution, and reproduction in any medium, provided you give appropriate credit to the original author(s) and the source, provide a link to the Creative Commons license, and indicate if changes were made. The Creative Commons Public Domain Dedication waiver (http://creativecommons.org/publicdomain/zero/1.0/) applies to the data made available in this article, unless otherwise stated. 
There are limited data on the burden of GDM in subSaharan Africa (SSA). In 2015, a review by Mwanri and colleagues suggested a prevalence of $14 \%$ among high risk individuals [14], but the prevalence in the general population is largely unknown. Similarly, the risk factors for GDM among Africans have not been adequately documented. Classical factors such as maternal age, overweight or obesity and family history for type 2 diabetes have been reported to be important risk factors of GDM in SSA [14], as they are in other populations [4]. It is possible that other local drivers such as malnutrition and infections may play a role, although these have not been sufficiently explored [15]. There is increasing evidence that undernutrition in early life can lead to later risk of cardio-metabolic disorders like diabetes [16]. Similarly, chronic infections (such as in HIV or TB that are highly prevalent in the region), perhaps via inflammation and immune activation, are thought to increase risk of diabetes [17].

GDM is known to adversely impact maternal and offspring outcomes [18]. Infants born to GDM women are more likely to be macrosomic i.e. birthweight $\geq 4.0 \mathrm{kgs}$ [19]. Macrosomic infants are more likely to suffer from birth-related injuries such as shoulder dystocia. They are also more likely to be admitted to the neonatal intensive care unit with metabolic complications [20]. Because of increased baby weight, women with GDM are more likely to deliver by caesarean section (CS) and to suffer from vaginal lacerations and postpartum haemorrhage. Most women with GDM revert to normal glycaemic status after giving birth, but they remain at increased risk of developing type 2 diabetes in the long term [2].

Since the review by Mwanri and colleagues was published, a number of studies have been published assessing the burden or risk factors of GDM in SSA (such as [21-24]); thus, there is need for integrating these new findings into what is already known from previous efforts. Furthermore, much as some studies have examined maternal and offspring outcomes of GDM in SSA, to our knowledge, no one has comprehensively summarised this evidence. Therefore, in this paper, we will provide a current update integrating new evidence on the burden and determinants of GDM in SSA (including the extent to which each identified risk factor increase GDM risk), as well as undertake a rigorous review of the impacts of GDM on maternal and offspring outcomes.

\section{Methods}

\section{Search strategy and selection criteria}

This systematic review and meta-analysis was registered with PROSPERO (2019: CRD42019116853) and carried following the Preferred Reporting Items for Systematic Reviews and Meta-Analyses (see filled PRISMA checklist in Additional files 1, [25]. We searched PubMed with the following search $(\mathrm{MeSH})$ terms: (diabetes mellitus) AND (pregnancy) AND (africa south of the saharah). We used a mixture of expanded MeSH terms and freetext words which are highlighted in Additional file 2. Thereafter, reference lists of relevant original research and review articles were looked into for more articles that suit our inclusion criteria. Further, additional studies were found through reverse-forward citation tracking i.e. checking recent publications and their references.

We included in this review any studies that: 1) were conducted in SSA countries according to the United Nations Statistics Division [26]; 2) reported prevalence or risk factors or outcomes of GDM as primary results; 3 ) were peer reviewed articles published in journals from inception to January 31st 2019; and, 4) had a sample size $\geq 100$ participants. We excluded from this review: 1) interventional studies including quasi-experimental studies and randomized trials; 2) case-series or case reports; 3) studies only including qualitative data, editorials, comments, letters and systematic reviews; and, 4) nonpeer reviewed studies; or, 5) animal research.

Relevant articles were identified from the search and then brought into EndNote version X7 after which duplicates were removed. The first two authors (BKN \& AAN) separately screened titles and abstracts to identify potentially eligible articles per the previously stated inclusion and exclusion criteria. Where there was no GDM prevalence (or risk factors or outcomes) information in the title or abstract, the reviewers examined the entire full text. Further deliberations were held with the senior author (MJN) to resolve any disagreements for a final consensus before including the full text article in the present review.

We employed the 22-item "Strengthening the Reporting of Observational Studies in Epidemiology (STROBE) checklist" [27] to assess the quality of included studies and guided by the published detailed explanation on how to use the checklist [28]. Two independent assessors (BKN \& AAN) evaluated the quality of included studies. The assessors discussed their scores and where they did not agree involved the senior author (MJN) in the discussion to reach a consensus. A quality assessment score out of 22 was determined for each study by assigning a point per addressed STROBE item; lower scores indicate relatively poor quality studies when compared to articles with higher scores. Studies scoring 14 or greater on the STROBE checklist were retained for further analyses while those scoring less than 14 were dropped.

BKN recorded the data from studies of moderate to high quality meeting our inclusion criteria into a data extraction form using $\mathrm{Excel}^{\circ}$, while AAN confirmed the correctness and comprehensiveness of the extracted data. The following study features were extracted: first 
author, year of publication, country, screening and diagnostic criteria for GDM, sample size and number of GDM cases and STROBE score. Other collected data important to risk factor analyses were the number of GDM cases exposed to a given risk factor (as well as the total number of exposed subjects) and number of cases unexposed to the risk factor (as well as the total number of unexposed subjects). To examine the adverse impacts of GDM, we also noted down the number of cases of the outcome (e.g. macrosomia or caesarian section births) exposed to GDM during the index pregnancy (as well the total exposed to GDM) and number of cases of the outcome not exposed to GDM (and the total unexposed to GDM).

\section{Data analysis}

We employed the random-effects meta-analysis as described by DerSimonian and Liard [29] to pool data on the burden (primarily prevalence), risk factors and outcomes of GDM in SSA. We report pooled point estimates of the prevalence and risk ratios (RRs) and their 95\%CIs for risk factor and outcome from included studies. The $\mathrm{I}^{2}$ index was used to assess heterogeneity across studies, higher $\mathrm{I}^{2}$ indicate increasing discrepancy due to variations across studies [30]. Meta-analyses for any of our studied outcomes or across subgroups were performed whenever there were at least 3 or more studies to combine; outcomes or subgroups with only two or fewer studies were not analyzed. For subgroups, we examined differences in GDM prevalence over time (studies published before 2009 and those from 2010 to 2018) and those using different diagnostic criteria (IADPSG/ WHO2013 versus other criteria). Statistical analyses were conducted in STATA version 15 (StataCorp, College Station TX). Since some selected studies had prevalence estimates at the $0 \%$ bound, we employed the metaprop command with Freeman-Tukey double arcsine transformation to pool prevalence across studies [31] whereas the metan command [32] was used to determine the RR and 95\%CIs for risk factors and outcomes of GDM in SSA.

\section{Results}

Initially, we identified 271 papers from PubMed (Fig. 1). Additional 12 papers were identified through reverseforward (recent) citations, checking of reference lists of relevant original papers and other reviews papers, adding up to 283 papers. After applying our inclusion and exclusion criteria, we ended up with 33 eligible articles [21-24, 33-61] for inclusion in this systematic review. Of these, 28 papers contributed towards estimation of GDM prevalence [21, 23, 24, 33-38, 40-42, 46-55, 57-61], 20 towards assessment of risk factors of GDM [21-24, 39, $41,44,45,47-50,52-55,57,58,60,61]$ and 6 towards the

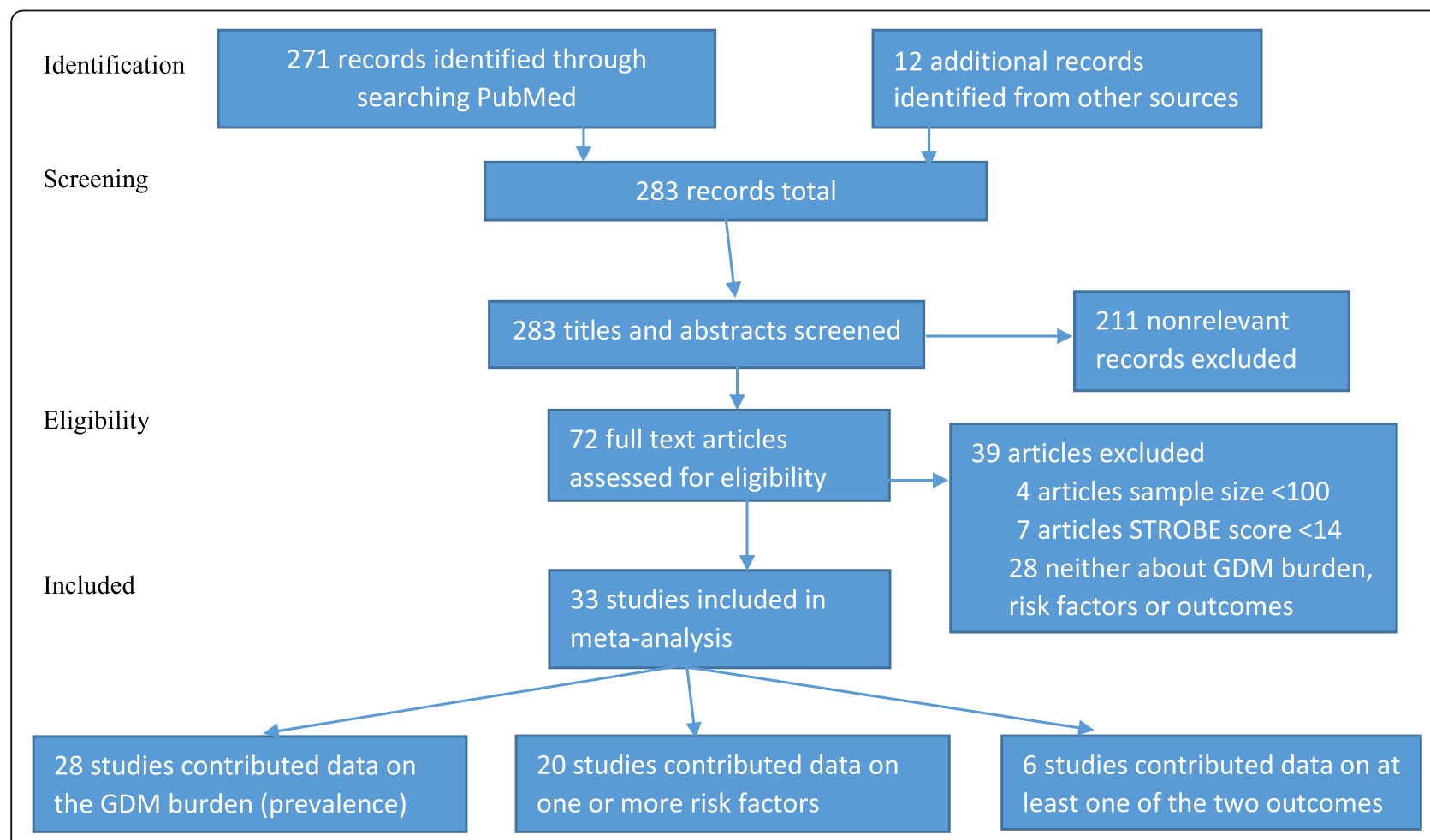

Fig. 1 PRISMA flow diagram showing the search process 
evaluation of the impacts of GDM on maternal and offspring outcomes [39, 43, 47, 51, 57, 61].

The 33 papers in this review have a total sample size of 31,821 women and 2146 GDM cases from 12 SSA countries (Table 1). Further, the median (interquartile range) sample size of included studies is 368 (251-890) participants. Eleven studies were published between 1969 and 2009 and 22 studies from 2010 to 2018. In terms of quality of included studies, article scores on the STROBE checklist are summarized in Table 1. The median (interquartile range) STROBE score was 17 (1518). The lowest STROBE score was 14 and the highest was 21 suggesting that included studies were of moderate to high quality.

The IADPSG/WHO 2013 diagnostic criteria for GDM were the mostly used (in 13 studies); these were followed by the WHO 1985 to WHO 2006 criteria (10 studies) and then the O'Sullivan \& Mahan criteria (or their adaptation by Carpenter and Coustan (CC) or the National Diabetes Data Group (NDDG)) in 5 studies. Fasting glucose (FG) concentrations alone were used to diagnose GDM in 4 studies. In one Ethiopian study [22], the screening and diagnostic criteria for GDM was not reported.

In terms of country of the study, 11 studies were from Nigeria alone [35, 39, 40, 42, 43, 45, 48, 50, 52, 54, 58], 8 studies from South Africa [24, 33, 34, 37, 41, 44, 59, 61] and 3 studies from Tanzania $[21,36,49]$. Cameroon [23, 47] and Ethiopia [22, 38] contributed two studies each. The other 7 countries (Democratic Republic of Congo [46], Djibouti [51], Ghana [53], Kenya [56], Rwanda [55], Uganda [57] and Zimbabwe [60]) contributed one study each.

\section{Prevalence of GDM in sub-Saharan Africa}

Our meta-analysis combining data from 28 studies estimates the overall prevalence of GDM in SSA to be $9 \%$ (95\%CI, 7-12\%) (Fig. 2). Further subgroup analyses suggest that the GDM prevalence is $3 \%(2-5 \%)$ in studies published between 1969 and 2009 and 13\% (9-17\%) for studies from 2010 to 2018 (Additional file 3). Looking at the diagnostic criteria used in included studies, studies employing the O'Sullivan and Mahan method (or its modification by Carpenter and Coustan or the National Diabetes Data Group) suggest a GDM prevalence of $4 \%$ (2-75\%); those using the WHO 1985 to WHO 2006 criteria have a combined prevalence of $4 \%(2-6 \%)$; and, those relying on fasting blood alone suggest a prevalence of $7 \%$ (6-9\%). On the other hand, studies using the IADPSG or WHO 2013 criteria have a combined GDM prevalence of 16\% (11-21\%) (Additional file 4).

\section{Risk factors for GDM in sub-Saharan Africa}

Twenty (20) included papers provide data on more than 14 different risk factors for GDM in SSA (with each risk factor having at least three different studies to combine), the results are summarized in Table 2, and details are given in Additional file 5. The most important risk factors for GDM in SSA based on the pooled analyses are history of GDM (5.9; 2.2-15.7), stillbirth (2.2; 1.4-3.4), macrosomia $(1.8 ; 1.3-2.5)$ and abortion $(1.8 ; 1.4-2.2)$ in prior pregnancies. Other important risk factors include family history of type 2 diabetes $(1.8 ; 1.4-2.3)$ and hypertension $(1.5 ; 1.2-2.1)$. Women older than 25 years (1.7; $1.2-2.4)$, those who are overweight or obese $(1.6 ; 1.2-$ $2.0)$ or multipara women $(1.4 ; 1.1-1.8)$ were at increased risk of GDM. Being primigravida is significantly associated with a reduced risk of GDM $(0.5 ; 0.3-0.9)$.

History of congenital anomaly in prior pregnancies (1.5; 0.4-4.8) and being HIV infected (1.1; 0.9-1.4) were associated with nonsignificant increases in the risk of GDM whereas having secondary or higher level of education $(0.8 ; 0.6-1.1)$ or being physically active $(0.4 ; 0.1-$ 1.8) were associated with nonsignicant lower risks of GDM.

\section{Outcomes of GDM in sub-Saharan Africa}

For only one maternal outcome (caesarian section (CS) delivery; 4 studies) and one offspring outcome (macrosomia; 5 studies) we found at least 3 or more studies to conduct a meta-analysis. We found that GDM results in a significant increase in the risk of giving birth to a macrosomic offspring (RR; 95\%CI: $2.19 ; 1.08-4.43$ ) as well as a nonsignificant increase in CS birth $(1.14 ; 1.0$ 1.4) (Additional file 6). We did not find any SSA studies that examined the impact of GDM beyond the time when the offspring is born.

\section{Discussion}

We estimate the prevalence of GDM in SSA to be 9\% (95\%CI: 7-12\%) with risk factors that include having a family history of type 2 diabetes and previous pregnancies complicated by GDM, macrosomia, stillbirth and abortion. Factors such as being overweight or obese, or older than 25 years or hypertensive were associated with a higher risk of GDM. Lastly, GDM women have increased risk of macrosomia in comparison to those without GDM.

Our meta-analytic approaches suggested a combined GDM prevalence of 9\%; however, there was a lot of heterogeneity ( $\mathrm{I}^{2}=96.9 \%$, Fig. 2$)$ among included studies. Possibly and because of this variability, differences in GDM prevalence can be seen in individual studies and exist across and within countries. It is as low as $0 \%$ in a Tanzania [36] and as high as $46 \%$ in Djibouti [51]. Even in the same country, different estimates of prevalence exist: 2 to 27\% in South Africa [41, 59]. We aimed to investigate potential sources of variation in studies on GDM prevalence via sub-group analyses. Based on when 


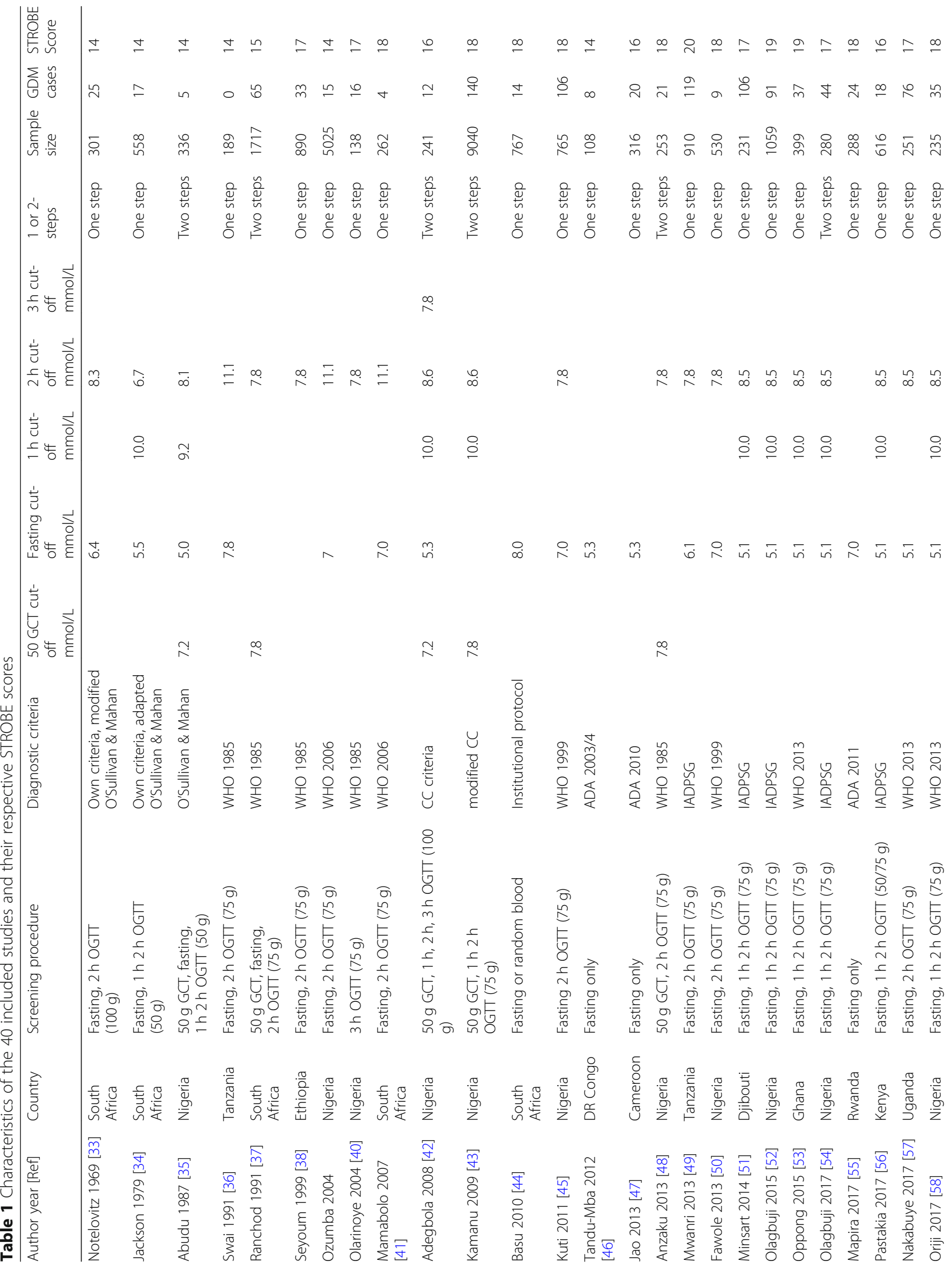




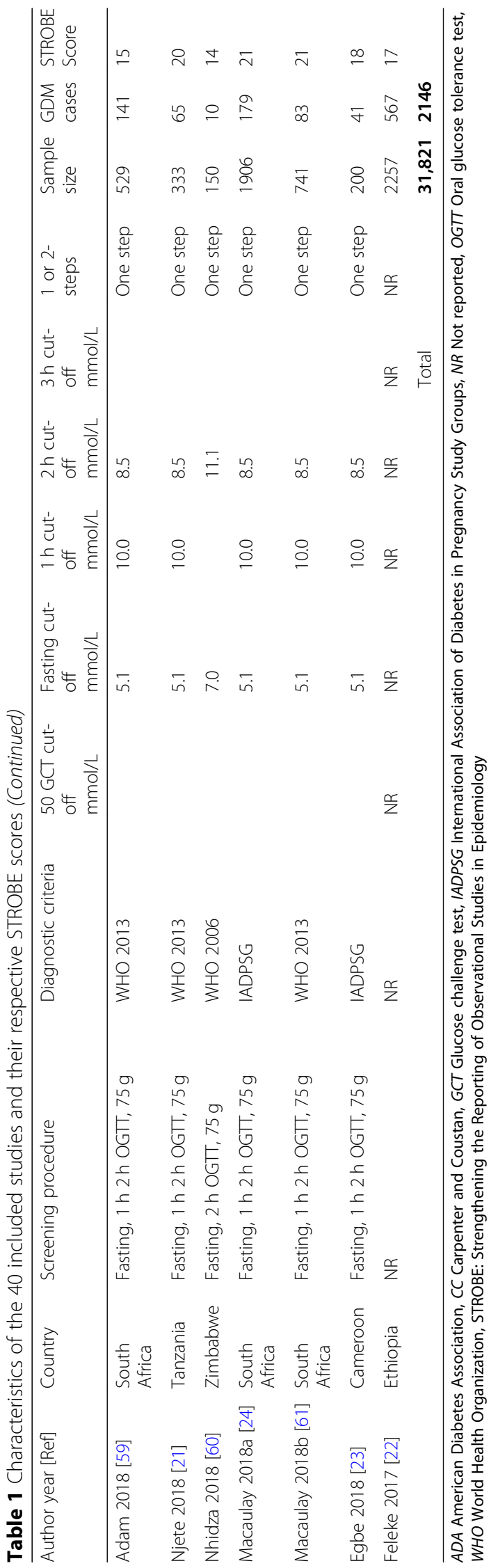




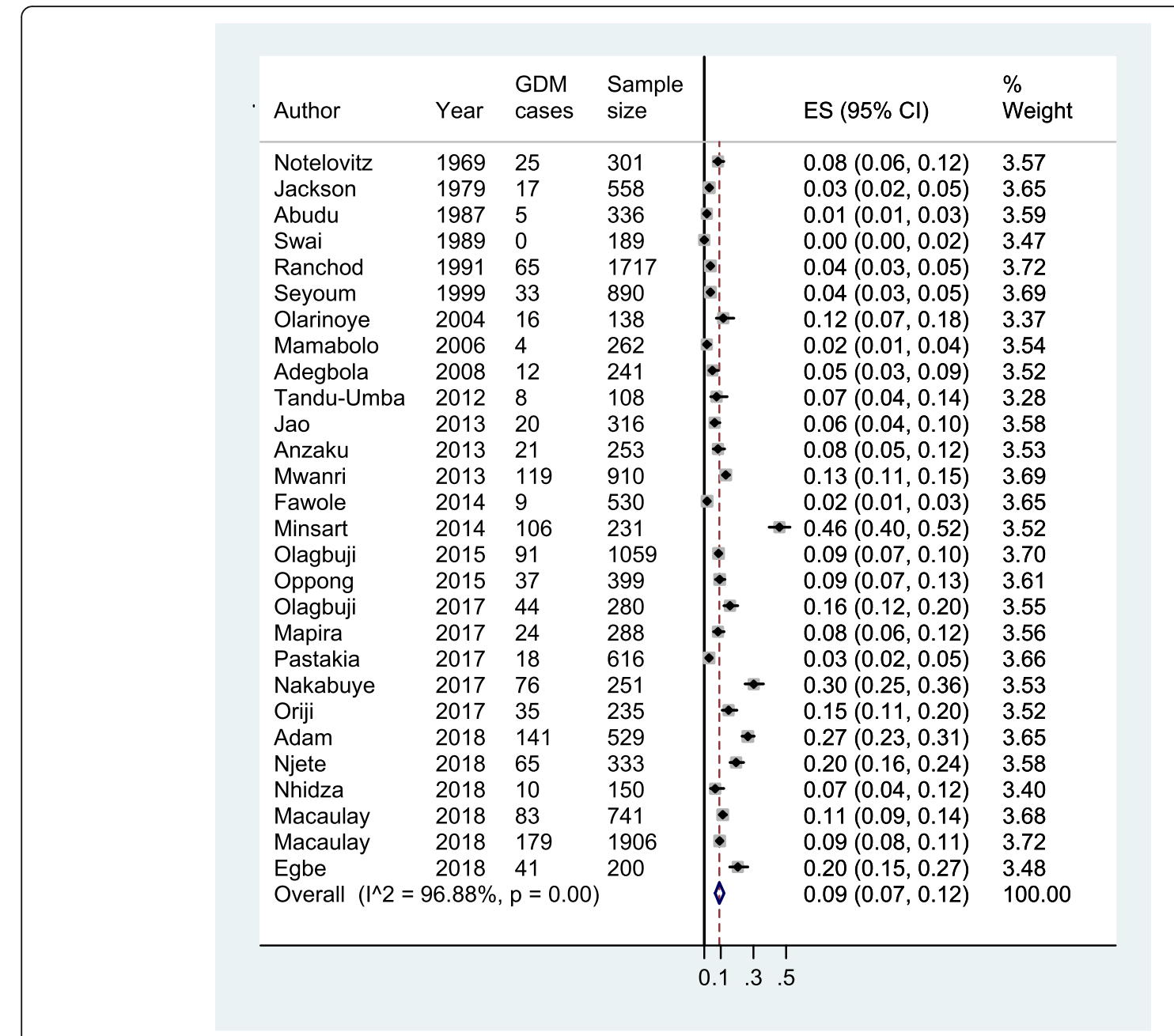

Fig. 2 Prevalence of GDM in sub-Saharan Africa

the study was published (a proxy of when the study took place), it appears the prevalence of GDM has increased significantly since around 2010 . This increase may reflect a true increase in the burden of GDM, for example, because of increasing prevalence of risk factors such as obesity. High rates of overweight and obesity among African women have been reported in some contexts in SSA [62]. Another source of heterogeneity might relate to recent changes in how GDM is screened and diagnosed. Indeed, as demonstrated in this review and others [4], adoption of the IADPSG criteria in 2010 has greatly influenced estimates of GDM burden, significantly increasing the number and proportion of individuals diagnosed with the condition.

Subgroup analyses related to when the study was conducted or diagnostic criteria did not help to eliminate the significant heterogeneity across studies in the subgroups ( $\mathrm{I}^{2}$ remained greater than $40 \%$ in most subanalyses). We performed meta-regression analyses (data not shown) to identify any further factors majorly influencing the estimate of GDM prevalence in the region. Meta-regression in this case considered both study (sample) size and study quality (STROBE score); however, neither variable was found to significantly influence the estimate of GDM prevalence. Meta-regression was considered not appropriate for analyses on the risk factors and complications associated with GDM. This is because there were very few studies included in each risk factor or complication analysis, and meta-regression requires many studies to implement [63]. Epidemiological approaches, rather than statistical methods, will be required to reduce variation across studies on GDM burden, determinants and complications in SSA. These will include, for example, more collaborative research, standardization of protocols and methodologies and studies conducted in more than one site within and across all SSA countries.

The estimated GDM prevalence in this review is lower than the $14 \%$ prevalence reported by Mwanri and colleagues for high risk women in SSA [14]; this should be 


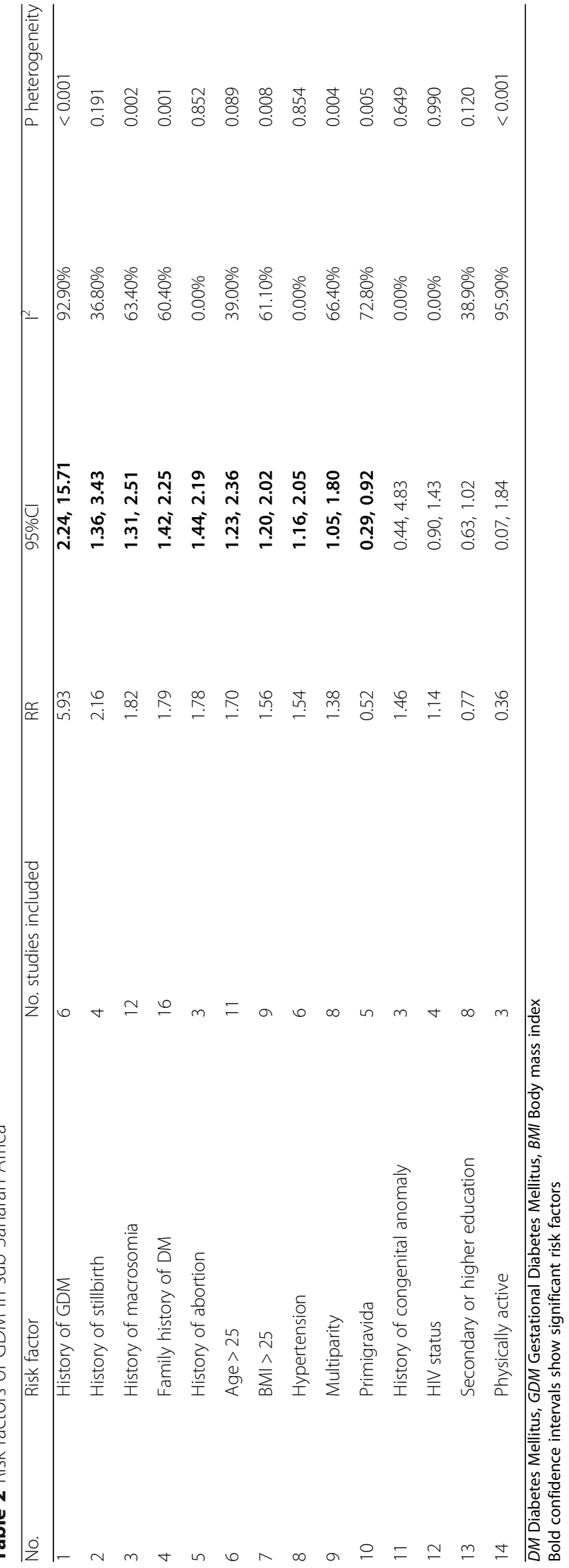


expected since our analyses were not restricted to the risk profile of participants in included studies. The combined prevalence of GDM this review is also lower than that reported for Asia (11.5\%) [4], but higher than that observed in European studies $(54 \%)$ [2, 3]. These discrepancies could be due to methodological variations, but may also reflect differences in susceptibility to GDM in different populations. For instance, it has been suggested that Asian women are more likely to develop GDM than their Caucasian or African-American counterparts [64].

Most of the identified risk factors for GDM in SSA (such as family history of type 2 diabetes, obstetric history factors, age and BMI category) are well-known determinants of GDM risk and have been studied in other contexts [4]. The direction and magnitude of effects of these factors would have been expected a priori; and, these classical factors will continue to guide risk factor based approaches to screening for GDM in SSA. However, few existing studies have examined non-classical risk factors for GDM among SSA populations. For example, there continues to be limited data exist on the impact of exposure to in-utero and early childhood undernutrition or chronic infections (such as HIV, malaria and others) and lifestyle factors (such as local patterns of smoking, alcohol and dietary intake) on GDM risk in SSA.

We found that GDM is significantly associated with increased risk of macrosomia and a non-significant increase in the risk of CS delivery. This is in accord with well-established literature [19]. However, delivery of large babies may represent a particular problem SSA contexts, where the burden of cephalopelvic disproportion is already high and access to obstetric and early neonatal care are still a major challenge [65].

This is the largest systematic review (to present) on the burden and risk factors of GDM in SSA. It is also the first to systematically summarize the risk that GDM poses on maternal and offspring outcomes. Although we only searched PubMed because it is publicly available and accessible to us, our paper includes more moderate to high quality studies than previous efforts on the topic [14]. Even then, there are still very few studies of good quality conducted in SSA (for example in comparison to studies carried out in Asia [4]) and most of the available evidence was generated from Nigeria and South Africa. Also, there were not enough SSA studies to combine and assess the impact of GDM on most neonatal morbidities including macrosomia or CS births [66] or on maternal and offspring outcomes that happen well after the neonatal period (such as risk of type 2 diabetes [2], infant adiposity [67] or breastfeeding rates [68]). As scientific awareness and attention to GDM increases in Africa, new high quality studies documenting the burden, risk factors and complications of GDM and in a breadth of African countries will emerge. This will enable future systematic reviewers to be more selective and report less variability across retrieved studies when estimating the burden, risk factors and impacts of GDM in the region.

\section{Conclusions}

Findings from this review suggest a GDM prevalence of 9\% in SSA and that GDM is, to a large extent, driven by classical risk factors of the disease in other contexts. Although there are limited data on neonatal outcomes, macrosomia appears to be a common complication. More SSA studies are clearly required to rigorously document trends in GDM prevalence, characterize risk factors (both classical and emerging) and to better understand impacts on the mother and her offspring.

\section{Supplementary information}

Supplementary information accompanies this paper at https://doi.org/10. 1186/s12884-019-2593-z.

Additional file 1. PRISMA checklist.

Additional file 2. Search strategy.

Additional file 3. Prevalence of GDM in sub-Saharan Africa, overall and by year of publication.

Additional file 4. Prevalence of GDM in sub-Saharan Africa, overall and by diagnostic criteria.

Additional file 5. Risk factors of GDM in sub-Saharan Africa

Additional file 6. Maternal and offspring outcomes of GDM in subSaharan Africa.

\section{Abbreviations}

CC: Carpenter and Coustan; CS: Caesarian Section birth; FG: Fasting Glucose; GCT: Glucose Challenge Test; GDM: Gestational Diabetes Mellitus;

IADPSG: International Association of Diabetes in Pregnancy Study Groups; NDDG: National Diabetes Data Group; OGTT: Oral Glucose Tolerance Test; RR: Risk Ratio; SSA: Sub-Saharan Africa; STROBE: Strengthening the Reporting of Observational Studies in Epidemiology; WHO: World Health Organization

\section{Acknowledgements}

Not applicable.

\section{Authors' contributions}

Conceived designed the study (BKN, MJN), extracted data (BKN, AAN), performed data analyses (BKN) and wrote the first draft of the manuscript (BKN). All authors (BKN, AAN, MJN) read the manuscript drafts for intellectual content, suggested revisions and approved the final draft for submission.

\section{Funding}

There was no funding source for this study. The corresponding author had full access to all the data in the study and had final responsibility for the decision to submit for publication.

\section{Availability of data and materials}

The datasets used and/or analyzed during the current study are available from the corresponding author on reasonable request.

Ethics approval and consent to participate Not applicable.

Consent for publication

Not applicable. 


\section{Competing interests}

The authors declare that they have no competing interests.

\section{Author details}

'MRC/UVRI and LSHTM Uganda Research Unit, Plot 51-59, Nakiwogo Road, PO Box 49, Entebbe, Uganda. ${ }^{2}$ Department of Noncommunicable Diseases EpidemiologyFaculty of Epidemiology and Population Health, London School of Hygiene and Tropical Medicine, London, UK.

\section{Received: 29 April 2019 Accepted: 11 November 2019}

\section{Published online: 28 November 2019}

\section{References}

1. World Health Organization: Definition, diagnosis and classification of diabetes mellitus and its complications: report of a WHO consultation. Part 1, Diagnosis and classification of diabetes mellitus. In.: Geneva: World health organization; 1999.

2. Zhu Y, Zhang C. Prevalence of gestational diabetes and risk of progression to type 2 diabetes: a global perspective. Current diabetes reports. 2016;16(1):7.

3. Eades CE, Cameron DM, Evans JM: Prevalence of gestational diabetes mellitus in Europe: A meta-analysis diabetes research and clinical practice 2017, 129:173-181

4. Lee KW, Ching SM, Ramachandran V, Yee A, Hoo FK, Chia YC, Sulaiman WAW, Suppiah S, Mohamed MH, Veettil SK. Prevalence and risk factors of gestational diabetes mellitus in Asia: a systematic review and meta-analysis. BMC pregnancy and childbirth. 2018;18(1):494.

5. O'Sullivan JB. Criteria for the oral glucose tolerance test in pregnancy. Diabetes. 1964;13:278-85.

6. National Diabetes Data Group. Classification and diagnosis of diabetes mellitus and other categories of glucose intolerance. Diabetes. 1979;28(12):1039-57.

7. Carpenter MW, Coustan DR. Criteria for screening tests for gestational diabetes. American Journal of Obstetrics \& Gynecology. 1982;144(7):768-73.

8. WHO Study Group on Diabetes Mellitus, World Health Organization: Diabetes mellitus: Report of a WHO Study Group. In. Geneva: World Health Organisation; 1985

9. International Association of Diabetes Pregnancy Study Groups Consensus Panel. International association of diabetes and pregnancy study groups recommendations on the diagnosis and classification of hyperglycemia in pregnancy. Diabetes Care. 2010;33(3):676-82.

10. American Diabetes Association: Standards of Medical Care in Diabetes -2010. 2010(33):S11-S61.

11. American Diabetes Association: Standards of medical care in diabetes-2011. Diabetes care 2011, 34(Supplement 1):S11-S61.

12. World Health Organization: Diagnostic criteria and classification of hyperglycaemia first detected in pregnancy. In. Geneva: World Health Organisation; 2013.

13. Coustan DR: Diagnosis of gestational diabetes. In: Nutrition and Diet in Maternal Diabetes: An Evidence Based Approach. edn. Edited by Rajendram R, Preedy VR, Patel VB. Cham, Switzerland Springer; 2018: 17-28.

14. Mwanri AW, Kinabo J, Ramaiya K, Feskens EJ. Gestational diabetes mellitus in sub-Saharan Africa: systematic review and metaregression on prevalence and risk factors. Tropical medicine \& international health : TM \& IH. 2015;20(8):983-1002.

15. Nyirenda MJ. Non-communicable diseases in sub-Saharan Africa: understanding the drivers of the epidemic to inform intervention strategies. Int Health. 2016;8(3):157-8.

16. Norris SA, Daar A, Balasubramanian D, Byass P, Kimani-Murage E, Macnab A, Pauw C, Singhal A, Yajnik C, Akazili J. Understanding and acting on the developmental origins of health and disease in Africa would improve health across generations. Glob Health Action. 2017;10(1):1334985.

17. Glennie SJ, Nyirenda M, Williams NA, Heyderman RS. Do multiple concurrent infections in African children cause irreversible immunological damage? Immunology. 2012;135(2):125-32.

18. Kampmann U, Madsen LR, Skajaa GO, Iversen DS, Moeller N, Ovesen P. Gestational diabetes: a clinical update. World J Diabetes. 2015;6(8):1065.

19. He X-J. Qin F-y, Hu C-L, Zhu M, Tian C-Q, li L: is gestational diabetes mellitus an independent risk factor for macrosomia: a meta-analysis? Arch Gynecol Obstet. 2015;291(4):729-35.

20. Kamana K, Shakya S, Zhang H. Gestational diabetes mellitus and macrosomia: a literature review. Ann Nutr Metab. 2015;66(Suppl. 2):14-20.

21. Njete HI, John B, Mlay P, Mahande MJ, Msuya SE. Prevalence, predictors and challenges of gestational diabetes mellitus screening among pregnant women in northern Tanzania. Tropical medicine \& international health : TM \& H. 2018;23(2):236-42.
22. Feleke BE. Determinants of gestational diabetes mellitus: a case-control study. The journal of maternal-fetal \& neonatal medicine : the official journal of the European Association of Perinatal Medicine, the Federation of Asia and Oceania Perinatal Societies, the International Society of Perinatal Obstet. 2018;31(19):2584-9.

23. Egbe TO, Tsaku ES, Tchounzou R, Ngowe MN. Prevalence and risk factors of gestational diabetes mellitus in a population of pregnant women attending three health facilities in Limbe, Cameroon: a cross-sectional study. Pan African Medical Journal. 2018:31(195).

24. Macaulay S, Ngobeni M, Dunger DB, Norris SA. The prevalence of gestational diabetes mellitus amongst black south African women is a public health concern. Diabetes Res Clin Pract. 2018;139:278-87.

25. Moher D, Liberati A, Tetzlaff J, Altman DG. Preferred reporting items for systematic reviews and meta-analyses: the PRISMA statement. Ann Intern Med. 2009:151(4):264-9.

26. United Nations Statistics Division. Countries or areas/geographic regions. 2019 [https://unstats.un.org/unsd/methodology/m49/]

27. Von Elm E, Altman DG, Egger M, Pocock SJ, Gøtzsche PC, Vandenbroucke JP, Initiative S. The strengthening the reporting of observational studies in epidemiology (STROBE) statement: guidelines for reporting observational studies. PLoS Med. 2007;4(10):e296.

28. Vandenbroucke JP, Von Elm E, Altman DG, Gøtzsche PC, Mulrow CD, Pocock SJ, Poole C, Schlesselman JJ, Egger M, Initiative S. Strengthening the reporting of observational studies in epidemiology (STROBE): explanation and elaboration. PLoS Med. 2007:4(10):e297.

29. DerSimonian R, Laird N. Meta-analysis in clinical trials. Control Clin Trials. 1986:7(3):177-88.

30. Higgins JP, Thompson SG. Quantifying heterogeneity in a meta-analysis Stat Med. 2002;21(11):1539-58.

31. Nyaga VN, Arbyn M, Aerts M. Metaprop: a Stata command to perform metaanalysis of binomial data. Archives of Public Health. 2014;72(1):39.

32. Sterne JA, Bradburn MJ, Egger M. Meta-analysis in Stata ${ }^{\top M}$. Systematic reviews in health care: meta-analysis in context. 2001:347-69.

33. Notelovitz M: Carbohydrate tolerance in the pregnant Natal Indian. South African medical journal = Suid-Afrikaanse tydskrif vir geneeskunde 1969, 43(13):367-371.

34. Jackson WP, Coetzee EJ: Gycosuria as an indication for glucose tolerance testing during pregnancy. South African medical journal = Suid-Afrikaanse tydskrif vir geneeskunde 1979, 56(22):921-923.

35. Abudu OO, Kuti JA. Screening for diabetes in pregnancy in a Nigerian population with a high perinatal mortality rate. Asia-Oceania journal of obstetrics and gynaecology. 1987;13(3):305-9.

36. Swai AB, Kitange HM, McLarty DG, Kilima PM, Masuki G, Mtinangi BL, Alberti $K G$. No deterioration of oral glucose tolerance during pregnancy in rural Tanzania. Diabetic medicine : a journal of the British Diabetic Association. 1991;8(3):254-7.

37. Ranchod HA, Vaughan JE, Jarvis P: Incidence of gestational diabetes at Northdale hospital, Pietermaritzburg. South African medical journal = SuidAfrikaanse tydskrif vir geneeskunde 1991, 80(1):14-16.

38. Seyoum B, Kiros K, Haileselase T, Leole A. Prevalence of gestational diabetes mellitus in rural pregnant mothers in northern Ethiopia. Diabetes Res Clin Pract. 1999;46(3):247-51.

39. Ozumba BC, Obi SN, Oli JM. Diabetes mellitus in pregnancy in an African population. International journal of gynaecology and obstetrics: the official organ of the International Federation of Gynaecology and Obstetrics. 2004;84(2):114-9.

40. Olarinoye JK, Ohwovoriole AE, Ajayi GO. Diagnosis of gestational diabetes mellitus in Nigerian pregnant women--comparison between $75 \mathrm{G}$ and $100 \mathrm{G}$ oral glucose tolerance tests. West Afr J Med. 2004;23(3):198-201.

41. Mamabolo RL, Alberts M, Levitt NS. Delemarre-van de Waal HA, Steyn NP. prevalence of gestational diabetes mellitus and the effect of weight on measures of insulin secretion and insulin resistance in third-trimester pregnant rural women residing in the central region of Limpopo Province, South Africa. Diabetic medicine : a journal of the British Diabetic Association. 2007:24(3):233-9.

42. Adegbola O, Ajayi GO. Screening for gestational diabetes mellitus in Nigerian pregnant women using fifty-gram oral glucose challenge test. West Afr J Med. 2008;27(3):139-43.

43. Kamanu Cl, Onwere S, Chigbu B, Aluka C, Okoro O, Obasi M. Fetal macrosomia in African women: a study of 249 cases. Arch Gynecol Obstet. 2009;279(6):857-61.

44. Basu JK, Jeketera CM, Basu D. Obesity and its outcomes among pregnant south African women. International journal of gynaecology and obstetrics: 
the official organ of the International Federation of Gynaecology and Obstetrics. 2010;110(2):101-4.

45. Kuti MA, Abbiyesuku FM, Akinlade KS, Akinosun OM, Adedapo KS, Adeleye JO, Adesina OA. Oral glucose tolerance testing outcomes among women at high risk for gestational diabetes mellitus. J Clin Pathol. 2011;64(8):718-21.

46. Tandu-Umba B, Mbangama Muela A. Outcome-based diagnosis of hyperglycemia in pregnancy in Kinshasa, Democratic Republic of Congo. Int J Gynecol Obstet. 2013;120(1):93-4.

47. Jao J, Wong M, Van Dyke RB, Geffner M, Nshom E, Palmer D, Muffih PT, Abrams EJ, Sperling RS, LeRoith D. Gestational diabetes mellitus in HIVinfected and-uninfected pregnant women in Cameroon. Diabetes Care. 2013;36(9):e141-2.

48. Anzaku AS, Musa J. Prevalence and associated risk factors for gestational diabetes in Jos, north-central, Nigeria. Arch Gynecol Obstet. 2013;287(5): 859-63.

49. Mwanri AW, Kinabo J, Ramaiya K, Feskens EJ. Prevalence of gestational diabetes mellitus in urban and rural Tanzania. Diabetes Res Clin Pract. 2014; 103(1):71-8.

50. Fawole AO, Ezeasor C, Bello FA, Roberts A, Awoyinka BS, Tongo O, Adeleye $\mathrm{JO}$, Ipadeola A. Effectiveness of a structured checklist of risk factors in identifying pregnant women at risk of gestational diabetes mellitus: a crosssectional study. Niger J Clin Pract. 2014;17(4):495-501.

51. Minsart AF. N'Guyen T S, Dimtsu H, Ratsimandresy R, dada F, Ali Hadji R: are the new IADPSG criteria for gestational diabetes useful in a country with a very high prevalence? Gynecological endocrinology : the official journal of the International Society of Gynecological Endocrinology. 2014;30(9):632-5.

52. Olagbuji BN, Atiba AS, Olofinbiyi BA, Akintayo AA, Awoleke JO, Ade-Ojo IP, Fasubaa OB. Prevalence of and risk factors for gestational diabetes using 1999, 2013 WHO and IADPSG criteria upon implementation of a universal one-step screening and diagnostic strategy in a sub-Saharan African population. Eur J Obstet Gynecol Reprod Biol. 2015;189:27-32.

53. Oppong SA, Ntumy MY, Amoakoh-Coleman M, Ogum-Alangea D, ModeyAmoah E. Gestational diabetes mellitus among women attending prenatal care at Korle-Bu teaching hospital, Accra, Ghana. International journal of gynaecology and obstetrics: the official organ of the International Federation of Gynaecology and Obstetrics. 2015;131(3):246-50.

54. Olagbuji BN, Aderoba AK, Kayode OO, Awe CO, Akintan AL, Olagbuji YW. Accuracy of 50-g glucose challenge test to detect International Association of Diabetes and Pregnancy Study Groups criteria-defined hyperglycemia. International journal of gynaecology and obstetrics: the official organ of the International Federation of Gynaecology and Obstetrics. 2017;139(3):312-7.

55. Mapira HT, Tumusiime DK, Yarasheski K, Rujeni N, Cade TW, Mutimura E. Strategy to improve the burden of gestational diabetes in African women: Rwandan perspective. Rwanda Journal. 2017:4(1):36-8.

56. Pastakia SD, Njuguna B, Onyango BA, Washington S, Christoffersen-Deb A, Kosgei WK, Saravanan P. Prevalence of gestational diabetes mellitus based on various screening strategies in western Kenya: a prospective comparison of point of care diagnostic methods. BMC Pregnancy Childbirth. 2017;17(1):226.

57. Nakabuye B, Bahendeka S, Byaruhanga R. Prevalence of hyperglycaemia first detected during pregnancy and subsequent obstetric outcomes at St. Francis Hospital Nsambya. BMC Res Notes. 2017;10(1):174.

58. Oriji VK, Ojule JD, Fumudoh BO. Prediction of gestational diabetes mellitus in early pregnancy: is abdominal skin fold thickness $20 \mathrm{~mm}$ or more an independent risk predictor? Journal of Biosciences and Medicines. 2017; 5(11):13.

59. Adam S, Rheeder P. Evaluating the utility of a point-of-care glucometer for the diagnosis of gestational diabetes. International journal of gynaecology and obstetrics: the official organ of the International Federation of Gynaecology and Obstetrics. 2018;141(1):91-6.

60. Nhidza G, Mutsaka K, Malunga G, Zhou DT. Diagnosis of Gestational Diabetes Mellitus in Urban Harare, Zimbabwe. The Open Public Health Journal. 2018:11(1).

61. Macaulay S. The effects of gestational diabetes mellitus on fetal growth and neonatal birth measures in an African cohort. J Hum Hypertens. 2018;35(10): $1425-33$.

62. Wesonga R, Guwatudde D, Bahendeka SK, Mutungi G, Nabugoomu F, Muwonge J. Burden of cumulative risk factors associated with noncommunicable diseases among adults in Uganda: evidence from a national baseline survey. Int J Equity Health. 2016;15(1):195.
63. Thompson SG, Higgins JP. How should meta-regression analyses be undertaken and interpreted? Stat Med. 2002:21(11):1559-73.

64. Makgoba M, Savvidou M, Steer P. An analysis of the interrelationship between maternal age, body mass index and racial origin in the development of gestational diabetes mellitus. BJOG Int J Obstet Gynaecol. 2012;119(3):276-82.

65. Kyei-Nimakoh M, Carolan-Olah M, McCann TV. Access barriers to obstetric care at health facilities in sub-Saharan Africa-a systematic review. Systematic reviews. 2017;6(1):110.

66. Persson B, Hanson U. Neonatal morbidities in gestational diabetes mellitus. Diabetes Care. 1998:21:B79

67. Wright CS, Rifas-Shiman SL, Rich-Edwards JW, Taveras EM, Gillman MW, Oken E. Intrauterine exposure to gestational diabetes, child adiposity, and blood pressure. Am J Hypertens. 2008;22(2):215-20.

68. Oza-Frank R, Moreland JJ, McNamara K, Geraghty SR, Keim SA. Early lactation and infant feeding practices differ by maternal gestational diabetes history. J Hum Lact. 2016;32(4):658-65.

\section{Publisher's Note}

Springer Nature remains neutral with regard to jurisdictional claims in published maps and institutional affiliations.

Ready to submit your research? Choose BMC and benefit from:

- fast, convenient online submission

- thorough peer review by experienced researchers in your field

- rapid publication on acceptance

- support for research data, including large and complex data types

- gold Open Access which fosters wider collaboration and increased citations

- maximum visibility for your research: over $100 \mathrm{M}$ website views per year

At BMC, research is always in progress.

Learn more biomedcentral.com/submissions 